\title{
Sistem Pendukung Keputusan Kelayakan Pemberian Asuransi Jiwa Untuk Nelayan dengan Menggunakan Metode Vikor (Studi Kasus: Dinas Kelautan dan Perikanan Medan)
}

\author{
Amatillah Nasution, Kurnia Ulfa \\ Program Studi Teknik Informatika, STMIK Budi Darma, Medan, Indonesia \\ Email: amatillahnst@gmail.com
}

\begin{abstract}
Abstrak- Asuransi jiwa adalah istilah yang digunakan untuk merujuk pada tindakan, sistem, atau bisnis di mana perlindungan finansial (atau ganti rugi secara finansial) untuk jiwa, properti, kesehatan dan lain sebagainya mendapatkan penggantian dari kejadian-kejadian yang tidak dapat diduga yang dapat terjadi seperti kematian, kehilangan, kerusakan atau sakit, di mana melibatkan pembayaran premi secara teratur dalam jangka waktu tertentu sebagai ganti polis yang menjamin perlindungan tersebut. Istilah "diasuransikan" biasanya merujuk pada segala sesuatu yang mendapatkan perlindungan. Sistem Pendukung Keputusan didefinisikan suatu sistem yang ditujukan untuk mendukung manajemen pengambilan keputusan, Pembuatan keputusan merupakan fungsi utama seorang manajer atau administrator. Kegiatan pembuatan keputusan meliputi pengidentifikasian masalah, pencarian alternatif penyelesaian masalah, evaluasi dari alternatif-alternatif tersebut dan pemilihan alternatif keputusan yang terbaikMetode metode Vise Kriterijumska Optimazacija Kompromisno Resenje (VIKOR) merupakan salah satu metode dari sekian metode yang di gunakan dalam pengambilan keputusan. Untuk menggunakan metode sistem pendukung keputusan harus memiliki kriteria-kriteria yang akan digunakan dalam penentuan-penentuan, selain itu harus menentukan tingkat kepentingan dari tiap-tiap kriteria. Sehingga sistem pendukung keputusan yang digunakan juga harus memiliki perencanaan komprehenshif dan terpadu untuk mengecilkan tingkat resiko kegagalan dan pemilihan keputusan.
\end{abstract}

Kata Kunci: Asuransi Jiwa, Nelayan, SPK, Vikor.

Abstract-Life insurance is a term used to refer to actions, systems, or businesses in which financial protection (or financial compensation) for life, property, health and so on gets reimbursed from unexpected events that can occur such as death, loss, damage or illness, which involves regular premium payments over a period of time in exchange for a policy that guarantees such protection. The term "insured" usually refers to everything that gets protection. Decision Support System is defined a system intended to support management decision making, Decision making is the main function of a manager or administrator. Decision making activities include identifying problems, finding alternative solutions to problems, evaluating these alternatives and choosing the best decision alternatives. The Vise Kriterijumska Optimazacija Kompromisno Resenje (VIKOR) method is one of the methods used in decision making. To use the decision support system method must have criteria that will be used in the determination, in addition it must determine the level of importance of each criterion. So the decision support system used must also have comprehensive and integrated planning to minimize the level of risk of failure and decision selection.

Keywords: Life Insurance, Fishermen, SPK, Vikor.

\section{PENDAHULUAN}

Nelayan merupakan aset bagi Indonesia dan nelayan juga salah satu faktor hal yang penting. Serta menjadi ujung tombak dalam pengembangan dibidang kelautan dan perikanan. Aktivitas para nelayan yang dilaut untuk menangkap ikan ini memiliki resiko tinggi yang bahkan biasa mengancam keselamatan jiwa. Meski nelayan sebagai salah satu faktor kunci dalam sektor kelautan dan perikanan, tapi kondisi nelayan di Indonesia masih belum dapat dikatakan sejahtera. Usaha nelayan sangat dipengaruhi oleh faktor alam, hal ini mengakibatkan hasil produksi tidak terjamin skala usaha nelayan kecil belum efesien dan memiliki produktifitas usaha yang rendah.

Untuk memenuhi kebutuhan nelayan pemerintahan dinas kelautan dan perikanan terus dituntut untuk memenuhi jaminan asuransi jiwa untuk nelayan seperti dana bantuan keselamatan untuk menjamin keluarga nelayan. Dana bantuan keselamatan jiwa adalah alternatif yang terbaik sebagai jaminan untuk nelayan, sehingga nelayan tidak merasa khawatir saat meninggalkan keluarga dalam mencari nafkah.

Kini era modern, kebutuhan asuransi jiwa menjadi kebutuhan primer. Tentu saja mengingat dari fungsi asuransi untuk memberikan perlindungan kepada pemegang polis, asuransi merupakan perjanjian antara penanggung dan tergantung yang mewajibkan tertanggung membayar sejumlah presmi untuk memberikan penggantian atas resiko kerugian, kerusakan, kematian ataupun kehilangan keuntungan yang diharapkan, yang mungkin terjadi atas peristiwa yang tidak diinginkan. Nelayan menjadi salah satu lapisan masyarakat yang jauh dari proteksi jiwa. Karena sampai saat ini pemerintahan pusat terutama (KKP) belum menyediakan asuransi jiwa untuk nelayan.

Dalam menentukan kelayakan penerima bantuan asuransi jiwa untuk nelayan Dinas perikanan dan kelautan perlu membuat sistem yang dapat mendukung pembuatan tersebut. Sistem pendukung keputusan merupakan salah satu sistem yang sangat efektif dalam mengelola data-data, dalam penyediaan masalah ini sistem pendukung keputusan dengan metode Vise Kriterijumska Optimazacija Kompromisno Resenje lebih cocok untuk menentukan penerimaan bantuan asuransi jiwa untuk nelayan pada Dinas kelautan dan perikanan.

Metode Vise Kriterijumska Optimazacija Kompromisno Resenje (VIKOR) merupakan salah satu metode dari sekian metode yang di gunakan dalam pengambilan keputusan. Untuk menggunakan metode sistem pendukung keputusan harus memiliki kriteria-kriteria yang akan digunakan dalam penentuan-penentuan, selain itu 
harus menentukan tingkat kepentingan dari tiap-tiap kriteria. Sehingga sistem pendukung keputusan yang digunakan juga harus memiliki perencanaan komprehenshif dan terpadu untuk mengecilkan tingkat resiko kegagalan dan pemilihan keputusan[1]-[3].

\section{METODE PENELITIAN}

\subsection{Sistem Pendukung Keputusan}

Secara umum Sistem Pendukung Keputusan di definisikan sebagai sebuah sistem yang mampu memberikan kemampuan baik kemampuan pemecahan masalah maupun kemampuan pengkomunikasian untuk masalah semiterstruktur. Secara khusus Sistem Pendukung Keputusan didefinisikan sebagai sebuah sistem yang mendukung kerja seorang manajer maupun sekelompok manajer dalam memecahkan masalah semi-terstruktur dengan cara memberikan informasi ataupun usulan menuju pada keputusan tertentu[4]-[7].

\subsection{Nelayan}

Nelayan merupakan orang-orang yang sehar-harinya bekerja menangkap ikan di laut maupun di air tawar ada banyak jenis-jenis nelayan yaitu :

1. Nelayan Kecil adalah nelayan yang melakukan penangkapan ikan untuk memenuhi kebutuhan hidup seharihari, baik yang tidak menggunakan kapal penangkap ikan berukuran paling besar 10 Gross Tonnage (GT).

2. Nelayan Tradisional adalah nelayan yang melakukan penangkapan ikan diperairan yang merupakan hak perikanan tradisional yang telah dimanfaatkan secara turun temurun sesuai dengan budaya dan kearifan lokal.

\subsection{Asuransi Jiwa}

Asuransi adalah istilah yang digunakan untuk merujuk pada tindakan, sistem, atau bisnis di mana perlindungan finansial (atau ganti rugi secara finansial) untuk jiwa, properti, kesehatan dan lain sebagainya mendapatkan penggantian dari kejadian-kejadian yang tidak dapat diduga yang dapat terjadi seperti kematian, kehilangan, kerusakan atau sakit, di mana melibatkan pembayaran premi secara teratur dalam jangka waktu tertentu sebagai ganti polis yang menjamin perlindungan tersebut. Istilah "diasuransikan" biasanya merujuk pada segala sesuatu yang mendapatkan perlindungan.

\subsection{Metode Vise Kriterijumska Optimazacija Kompromisno Resenje (VIKOR)}

VIKOR (Vise Kriterijumska Optimizacija I Kompromisno Resenje) adalah metode optimasi multi- kriteria yang digunakan dalam sistem yang kompleks. Metode ini berfokus pada perangkingan dan memilih dari satu set alternatif, dan menentukan solusi kompromi untuk masalah kriteria yang bertentangan, yang dapat membantu para pengambil keputusan untuk mencapai keputusan akhir. Di sini, solusi kompromi adalah solusi yang layak yang paling dekat dengan ideal, dan kompromi berarti perjanjian didirikan dengan saling konsesi[8]-[12].

Langkah-langkah yang digunakan dalam metode VIKOR[13]-[22], sebagai berikut:

1. Normalisasi matrik dengan cara nilai terbaik dalam satu kriteria dikurangi dengan nilai data sampel i kriteria j, lalu dibagi dengan nilai terbaik dalam satu kriteria dikurangi dengan nilai terjelek dalam satu kriteria.

$$
R_{i j}=\frac{\left(\max \mathrm{x}_{\mathrm{ij}}-\mathrm{X}_{\mathrm{ij}}\right)}{\left(\max \mathrm{x}_{\mathrm{ij}}-\min \mathrm{X}_{\mathrm{ij}}\right)}
$$

Dimana :

$$
\begin{array}{ll}
\mathrm{R}_{\mathrm{ij}} & \text { : nilai normalisasi sampel } i \text { kriteria } j \\
\mathrm{X}_{\mathrm{ij}} & : \text { nilai data sampel } i \text { kriteria } j \\
\operatorname{Max} \mathrm{X}_{\mathrm{ij}} & \text { : nilai terbaik dalam satu kriteria } \\
\operatorname{Min} \mathrm{X}_{\mathrm{ij}} & : \text { nilai terjelek dalam satu kriteria } \\
\mathrm{i} & : \text { alternatif } \\
\mathrm{j} & : \text { kriteria }
\end{array}
$$

2. Menghitung nilai Utility Measure (S) dan Regret Measure (R). menghitung utility measure dengan cara menjumlah hasil dari perkalian bobot dengan hasil normalisasi matrik, menghitung regret measure dengan cara mencari nilai maksimal dari perkalian bobot dengan hasil normalisasi.

$\mathrm{W}_{\mathrm{j}} * \mathrm{R}_{\mathrm{ij}}$

$S_{i}=\sum_{j=1}^{n} W_{j} * R_{i j}$

Dimana :

$\mathrm{W}_{j}$ : bobot kriteria

$\mathrm{R}_{i}=\max \left[\mathrm{w}_{\mathrm{j}} * \mathrm{R}_{\mathrm{ij}}\right]$

3. Menghitung indeks vikor dengan cara nilai $S$ dikurangi nilai $S$ terkecil lalu dibagi dengan nilai $S$ terbesar dikurangi dengan nilai $\mathrm{S}$ terkecil dan dikali $\mathrm{v}$ dan dijumlahkan dengan nilai $\mathrm{R}$ dikurangi nilai $\mathrm{R}$ terkecil lali dibagi dengan nilai $\mathrm{R}$ terbesar dikurangi nilai $\mathrm{R}$ terkecil dan dikali dengan 1 dikurangi v. 
$Q_{i}=\frac{\left(S_{i}-S_{i} \min \right)}{\left(S_{i} \max -S_{i} \min \right)} * v+\frac{\left(R_{i}-R_{i} \min \right)}{\left(R_{i} \max -R_{i} \min \right)} *(1-v)$

Dimana :

$\mathrm{V}: 0.5$

$\mathrm{S}_{\mathrm{i}} \min \quad:$ nilai $\mathrm{S}$ terkecil

$\mathrm{S}_{\mathrm{i}} \max \quad$ : nilai $\mathrm{S}$ terbesar

$\mathrm{R}_{\mathrm{i}} \min \quad$ : nilai $\mathrm{R}$ terkecil

$\mathrm{R}_{\mathrm{i}} \max \quad$ : nilai $\mathrm{R}$ terbesar

Sampel dengan nilai $\mathrm{Q}$ terkecil merupakan sampel terbaik.

4. Merangking Alternatif

Mengusulkan Solusi kompromi alternatif yang memiliki peringkat terbaik dengan mengukur indek Vikor yang minimum.

\section{HASIL DAN PEMBAHASAN}

Pada desain berbasis komputer Analisa sistem memegang peranan penting dalam rincian sistem baru. Analisa sisitem merupakan proses pemecahan sistem menjadi subsistem yang ruang lingkupnya lebih kecil, dengan maksud agar lebih mudah dalam mengidentifikasi permasalahan, hambatan dan kesempatan-kesempatan yang ada didalam sistem.

1. Data Alternatif

Tabel 1. Data Alternatif

2. Data Kriteria

\begin{tabular}{cl}
\hline Kriteria $(\mathrm{C})$ & Keterangan \\
\hline C1 & Awaluddin Samosir \\
C2 & Hamdan Panjaitan \\
C3 & Ayaan \\
C4 & Muhammad Nuh marpaung \\
C5 & Sunario \\
\hline
\end{tabular}

Tabel 2. Data Kriteria

\begin{tabular}{clc}
\hline Kreteria & Keterangan & Bobot \% \\
\hline C1 & Usia & 30 \\
C2 & Ahli Waris & 15 \\
C3 & Kartu tabungan & 10 \\
C4 & Kartu Nelayan & 25 \\
C5 & Tanggungan & 20 \\
\hline
\end{tabular}

3. Bobot

Tabel 3. Nilai Bobot

\begin{tabular}{ll}
\hline Range & Nilai $(\%)$ \\
\hline Sangat buruk & 0,25 \\
Buruk & 0,3 \\
Cukup & 0,4 \\
Baik & 0,5 \\
Sangat baik & 0,7 \\
\hline
\end{tabular}

4. Rating Kecocokan

Tabel 4. Rating Yang Telah Dibobotkan

\begin{tabular}{llllll}
\hline & & & \multicolumn{2}{l}{ Kriteria } & \\
Alternatif & C1 & C2 & C3 & C4 & C5 \\
\hline A1 & 0.9 & 0.5 & 0.81 & 0.95 & 0.7 \\
A2 & 0.5 & 0.7 & 0.78 & 0.5 & 0.72 \\
A3 & 0.95 & 0.5 & 0.81 & 0.7 & 0.81 \\
A4 & 0.81 & 0.5 & 0.5 & 0.81 & 0.7 \\
A5 & 0.5 & 0.95 & 0.91 & 0.81 & 0.7 \\
Max & 0.95 & 0.95 & 0.91 & 0.95 & 0.81 \\
Min & 0.5 & 0.5 & 0.5 & 0.5 & 0.7 \\
\hline
\end{tabular}

5. Penyelesaian dengan Metode VIKOR

Dari tabel nilai masing-masing kriteria akan dilakukan normalisasi data,yaitu: 
a. Melakukan normalisasi data

Kriteria untuk C1

$$
\begin{aligned}
& \text { R A1,C1 }=\frac{(0.95-0.9)}{(0.95-0.5)}=\frac{0.05}{0.45}=0.11 \\
& \text { RA2,C1 }=\frac{(0.95-0.5)}{(0.95-0.5)}=\frac{0.45}{0.45}=1 \\
& \text { R A3,C1 }=\frac{(0.91-0.81)}{(0.91-0.5)}=\frac{0.1}{0.41}=0.24 \\
& \text { R A4,C1 }=\frac{(0.95-0.95)}{(0.95-0.5)}=\frac{0}{0.45}=0 \\
& \text { R A5,C1 }=\frac{(0.81-0.7)}{(0.81-0.7)}=\frac{0.11}{0.11}=1
\end{aligned}
$$

Kriteria untuk $\mathrm{C} 2$

$$
\begin{aligned}
& \text { R A1,C2 }=\frac{(0.95-0.5)}{(0.95-0.5)}=\frac{0.45}{0.45}=1 \\
& \text { R A2,C2 }=\frac{(0.95-0.7)}{(0.95-0.5)}=\frac{0.25}{0.45}=0.55 \\
& \text { R A3,C2 }=\frac{(0.91-0.78)}{(0.91-0.5)}=\frac{0.13}{0.41}=0.31 \\
& \text { R A4,C2 }=\frac{(0.95-0.5)}{(0.95-0.5)}=\frac{0.45}{0.45}=1 \\
& \text { R A5,C2 }=\frac{(0.81-0.72)}{(0.81-0.7)}=\frac{0.09}{0.11}=0.81
\end{aligned}
$$

Dengan langkah-langkah perhitungan diatas maka di dapat data normalisasi semua sample, berikut disajikan tabel data normalisasi semua sample (normalisasi matriks).

Tabel 5. Hasil Normalisasi Matriks

\begin{tabular}{cccccc}
\hline & \multicolumn{5}{c}{ Kriteria } \\
\cline { 2 - 6 } Alternatif & C1 & C2 & C3 & C4 & C5 \\
\hline A1 & 0.11 & 1 & 0.24 & 0 & 1 \\
A2 & 1 & 0.55 & 0.31 & 1 & 0.81 \\
A3 & 2.22 & 1 & 0.24 & 0.55 & 0 \\
A4 & 0.31 & 1 & 1 & 0.31 & 1 \\
A5 & 1 & 0 & 0 & 0.31 & 1 \\
\hline
\end{tabular}

Tabel 6. Normalisasi X Bobot

\begin{tabular}{cccccc}
\hline & \multicolumn{5}{c}{ Kriteria } \\
\cline { 2 - 6 } Alternatif & $\mathrm{C} 1$ & $\mathrm{C} 2$ & $\mathrm{C} 3$ & $\mathrm{C} 4$ & $\mathrm{C} 5$ \\
\hline A1 & $0.11 * 0.3$ & $1 * 0.15$ & $0.24 * 0.1$ & $0 * 0.25$ & $1 * 0.2$ \\
A2 & $1 * 0.3$ & $0.55 * 0.15$ & $0.31 * 0.1$ & $1 * 0.25$ & $0.81 * 0.2$ \\
A3 & $2.22 * 0.3$ & $1 * 0.15$ & $0.24 * 0.1$ & $0.55 * 0.25$ & $0 * 0.2$ \\
A4 & $0.31 * 0.3$ & $1 * 0.15$ & $1 * 0.1$ & $0.31 * 0.25$ & $1 * 0.2$ \\
A5 & $1 * 0.3$ & $0 * 0.15$ & $0 * 0.1$ & $0.31 * 0.25$ & $1 * 0.2$ \\
\hline
\end{tabular}

Tabel 7. Normalisasi X Bobot Kriteria

\begin{tabular}{cccccc}
\hline & \multicolumn{5}{c}{ Kriteria } \\
\cline { 2 - 6 } Alternatif & $\mathrm{C} 1$ & $\mathrm{C} 2$ & $\mathrm{C} 3$ & $\mathrm{C} 4$ & $\mathrm{C} 5$ \\
\hline A1 & 0.033 & 0.15 & 0.024 & 0 & 0.2 \\
A2 & 0.3 & 0.082 & 0.031 & 0.25 & 0.162 \\
A3 & 0.666 & 0.15 & 0.024 & 0.137 & 0 \\
A4 & 0.093 & 0.15 & 0.1 & 0.077 & 0.2 \\
A5 & 0.3 & 0 & 0 & 0.077 & 0.2 \\
\hline
\end{tabular}

b. Menghitung Nilai $\mathrm{S}$ dan $\mathrm{R}$

Rumus $\mathrm{S}_{\mathrm{i}}=\sum_{j=1}^{n}$ wj $x(R i j)$

wj $=$ bobot kriteria

Nilai S didapatkan dari penjumlahan hasil perkalian bobot kriteria dengan data pada setiap sample.

$$
\begin{aligned}
\mathrm{S}(\mathrm{A} 1) & =0.033+0.15+0.024+0+0.2 \\
& =0.407 \\
\mathrm{~S}(\mathrm{~A} 2) & =0.3+0.082+0.031+0.25+0.162 \\
& =0.825 \\
\mathrm{~S}(\mathrm{~A} 3) & =0.666+0.15+0.024+0.137+0 \\
& =0.977
\end{aligned}
$$




$$
\begin{aligned}
S(A 4) & =0.93+0.15+0+0.07+0.2 \\
& =0.62 \\
S(A 5) & =0.3+0+0+0.077+0.2 \\
& =0.577
\end{aligned}
$$

Rumus $\mathrm{R} i=\operatorname{Max} j[\mathrm{w} j \mathrm{x} i j]$

Nilai R adalah nilai terbesar dari perkalian bobot kriteria dengan data normalisasi dari setiap alternatif.
$\mathrm{R}(\mathrm{C} 1)=0.2$
$\mathrm{R}(\mathrm{C} 2)=0.3$
$\mathrm{R}(\mathrm{C} 3)=0.666$
$\mathrm{R}(\mathrm{C} 4)=0.2$
$\mathrm{R}(\mathrm{C} 5) \quad=0.3$

Tabel 8. Nilai S dan R

\begin{tabular}{cll}
\hline Alternatif & Nilai S & Nilai R \\
\hline A1 & $\mathbf{0 . 4 0 7}$ & $\mathbf{0 . 2}$ \\
A2 & 0.825 & 0.3 \\
A3 & $\mathbf{0 . 9 7 7}$ & $\mathbf{0 . 6 6 6}$ \\
A4 & 0.62 & 0.2 \\
A5 & 0.577 & 0.3 \\
\hline
\end{tabular}

Pada tabel diatas, terdapat nilai data yang dipertebal atau ditandai. Keduan data tersebut masing-masing adalah nilai terbesar dan terkecil dari nilai $\mathrm{S}$ dan $\mathrm{R}$.

c. Menghitung indeks

Rumus $\mathrm{Q}_{\mathrm{i}}=\left[\frac{S_{i}-S^{+}}{S^{-}-S^{+}}\right] \mathrm{v}+\left[\frac{R_{i}-R^{+}}{R^{-}-R^{+}}\right](1-\mathrm{v})$

Keterangan :

$\mathbf{S}^{-}=$nilai $\mathrm{S}$ terbesar $\mathbf{R}^{-}=$nilai $\mathrm{R}$ terbesar

$\mathbf{S}^{+}=$nilai $\mathbf{S}$ terkecil $\mathbf{R}^{+}=$nili $\mathbf{R}$ terkecil

Alternatif dengan nilai Q terkecil merupakan alternatif terbaik. Berikut perhitungan nilai indeks Vikor (Q):

$\mathrm{Q}(\mathrm{A} 1)=((0.407-0.407 / 0.997-0.407) *(0.5))+(0.2-0.2 / 0.666-0.2) *(1-0.5))$

$=((0 / 0.57) *(0.5))+(0 / 0.466) *(1-0.5))$

$=((0 * 0.5)+(0 * 0.5))$

$=0+0$

$=0$

$\mathrm{Q}$ (A2) $=((0.418-0.407 / 0.997-0.407) *(0.5))+(0.3-0.2 / 0.666-0.2) *(1-0.5))$

$=((0.418 / 0.59) *(0.5))+(0.1 / 0.466) *(1-0.5))$

$=(0.708 * 0.5)+(0.214 * 0.5)$

$=0.354+0.107$

$=0.461$

Tahapan selanjutnya setelah melakukan perhitungan indeks Vikor (Q) diatasadalah melakukan perangkingan berdasarkan nilai Vikor (Q) paling kecil.

Tabel 9. Perangkingan Indeks Vikor

\begin{tabular}{llc}
\hline Alternatif & Nilai Q & Peringkat \\
\hline Awaluddin & 0 & 1 \\
Hamdan & 0.461 & 4 \\
Ayaan & 0.983 & 5 \\
Muhammad Nuh & 0.18 & 2 \\
Sunariyo & 0.251 & 3 \\
\hline
\end{tabular}

Berdasarkan perangkingan Indeks Vikor diatas diperoleh nilai terbesar adalah (Alternatif A1) atas nama Awaluddin. Maka berdasarkan sistem pendukung keputusan menggunakan metode Vikor, Anto layak mendapatkan asuransi jiwa.

\section{KESIMPULAN}

Berdasarkan hasil penelitian yang telah dilakukan penulis dapat diambil kesimpulan bahwa penerapan metode vikor cukup mudah digunakan sebagai cara untuk pemberian asuransi jiwa kepada nelayan.

\section{REFERENCES}

[1] M. Yazdani and F. R. Graeml, "VIKOR and its Applications," Int. J. Strateg. Decis. Sci., vol. 5, no. 2, pp. 56-83, Apr. 2014.

[2] G.-H. Tzeng and J.-J. Huang, Multiple Attribute Decision Making Method And Applications. CRC Press, 2011. 
[3] Y. J. B. Parrangan et al., "The Implementation of MIKOR method to Improve the Effectiveness of Sidi learning Graduation," Int. J. Eng. Technol., vol. 7, no. 3.4 Special Issue 4, 2018.

[4] T. Limbong et al., Sistem Pendukung Keputusan: Metode \& Implementasi. Medan: Yayasan Kita Menulis, 2020

[5] Efraim Turban and Jay E. Aronson, Decision Support System and Intelligent Systems. 2001.

[6] S. Kusumadewi, S. Hartati, A. Harjoko, and Retantyo Wardoyo, Fuzzy Multi-Attribute Decision Making (FUZZY MADM). 2006.

[7] Kusrini, Konsep dan Aplikasi Sistem Pendukung Keputusan. 2007.

[8] Mesran, K. Ulfa, D. P. Utomo, and I. R. Nasution, "Penerapan Metode VlseKriterijumska Optimizacija I Kompromisno Resenje ( Vikor ) Dalam Pengangkatan Guru,” Algoritm. J. Ilmu Komput. dan Inform., vol. 4, no. 1, pp. 265-271, 2020.

[9] A. A. Trisnani, D. U. Anwar, W. Ramadhani, M. M. Manurung, and A. P. U. Siahaan, "Sistem Pendukung Keputusan Pemilihan Karyawan Berprestasi Menerapkan Metode Vise Kriterijumska Optimizajica I Kompromisno Resenje (VIKOR)," JURIKOM (Jurnal Ris. Komputer), vol. 5, no. 2, pp. 85-90, Apr. 2018.

[10] T. Imandasari and A. P. Windarto, "Penerapan Metode VIKOR Pada Pemilihan Popok Bayi Berdasarkan Jenis Kulit," pp. 215-220, 2018.

[11] A. Siregar, P. Ginting, M. Mesran, and L. T. Sianturi, "Implementasi Metode Vikor Dalam Pemilihan Supplier Bahan Baku," KOMIK (Konferensi Nas. Teknol. Inf. dan Komputer), vol. I, pp. 132-138, 2017.

[12] M. Sianturi, S. Wulan, Suginam, Rohminatin, and Mesran, "Implementasi Metode VIKOR Untuk Menentukan Bahan Kulit Terbaik Dalam Pembuatan Ikat Pinggang," J. Ris. Komput., vol. 5, no. 1, pp. 56-60, 2018.

[13] W. Jingzhu and L. Xiangyi, "The multiple attribute decision-making VIKOR method and its application," in 2008 International Conference on Wireless Communications, Networking and Mobile Computing, WiCOM 2008, 2008

[14] I. Wijaya and Mesran, "Penerapan Metode AHP dan VIKOR Dalam Pemilihan Karyawan Berprestasi," in Seminar Nasional Teknologi Komputer \& Sains (SAINTEKS), 2019, pp. 301-309.

[15] M. F. El-santawy, "A VIKOR Method for Solving Personnel Training," Int. J. Comput. Sci., vol. 1, no. 2, pp. 9-12, 2012

[16] D. Siregar et al., "Multi-Attribute Decision Making with VIKOR Method for Any Purpose Decision," in 1st International Conference on Green and Sustainable Computing (ICoGeS) 2017, 2018, vol. 1019, no. 1.

[17] M. Mesran et al., "The VIKOR Method to Support the Effectiveness of Decisions in Determining Work Incentive Recipients," J. Phys. Conf. Ser., vol. 1175, p. 012043, 2019.

[18] A. Siregar, P. Ginting, Mesran, and L. T. Sianturi, "Implementasi Metode Vikor Dalam Pemilihan Supplier Bahan Baku," KOMIK (Konferensi Nas. Teknol. Inf. dan Komputer), vol. I, pp. 132-138, 2017.

[19] A. Mardani, E. Zavadskas, K. Govindan, A. Amat Senin, and A. Jusoh, "VIKOR Technique: A Systematic Review of the State of the Art Literature on Methodologies and Applications," Sustainability, vol. 8, no. 1, p. 37, Jan. 2016

[20] S. P. Lengkong, A. E. Permanasari, and S. Fauziati, "Implementasi Metode VIKOR untuk Seleksi Penerima Beasiswa," Proc. 7 th Natl. Conf. Inf. Technol. Electr. Eng., vol. 33, pp. 107-112, 2015.

[21] H. Tumanggor, M. Haloho, P. Ramadhani, and S. D. Nasution, "Penerapan Metode VIKOR Dalam Penentuan Penerima Dana Bantuan Rumah Tidak Layak Huni," vol. 5, no. 1, pp. 71-78, 2018.

[22] K. Umam, V. E. Sulastri, T. Andiri, D. U. Sutiksno, and Mesran, "Perancangan Sistem Pendukung Keputusan Penentuan Prioritas Produk Unggulan Daerah Menggunakan Metode VIKOR,” J. Ris. Komput., vol. Vol 5, no. 1, pp. 43-49, 2018. 